\title{
The Remanufacturing Research on the Key Parts of Engineering Machinery \\ Xin-min $\mathrm{CAO}^{1, \text { a }}$ \\ ${ }^{1}$ Guangxi Technical College of Machinery and electricty,Nanning 530007 ,China \\ axinmincao@126.com
}

Keywords: Remanufacturing, Engineering Machinery, Key Parts

\begin{abstract}
With the rapid development of construction machinery industry, especially as domestic rapid economic and social development of the strong demand for engineering machinery, engineering machinery manufacturing industry is facing pressure from various resources saving and environment friendly requirements, development of remanufacturing technology, to carry out the green remanufacturing technology for engineering machinery research and development and application is more urgent. Because of the construction machinery's huge and continue to increase, reason for remanufacturing, make full use of the materials of the surplus value has important economic significance and social significance.
\end{abstract}

\section{Introduction}

Engineering machinery as an important part of the machinery industry, has become an increasingly important role in the economic construction, with the steady growth of economy, engineering machinery industry also showed vigorous vitality. Engineering machinery usually exists the weight more than large, production material consumption, retired after the big issues such as environmental pollution [1]. On the one hand, engineering machinery is generally fast update, there are a lot of equipment due to not adapt to the needs of the development of social economy, in has yet to reach its design life of the retired in advance; Engineering machinery parts, on the other hand, the number is more, the service life of the parts, after the machine scrap, there are quite a number of parts can be directly recycled or reprocessing, it can greatly improve the utilization rate of resources, reduce waste mechanical the damage to the environment, at the same time also can improve the economic benefit of enterprise.

Remanufacturing engineering as an important part of green design, is in order to save resources, save energy and protect environment as characteristic, since entering the China, combining with the current our country the requirements of sustainable development, is accepted by more and more enterprises, and into the actual production process [2]. Remanufacturing engineering involved in automobile, machine tools, engineering machinery and other fields, including in the field of engineering machinery, the traditional product design mainly depends on the designers have the relevant design objects involved in the field of professional knowledge, and mostly focus on product after put into use to keep it, becomes available status or be reused or a series of technical measures taken by engineering activities, and put into use before the design work of product is less concerned and studied.

\section{The basic theory of remanufacturing}

America first proposed the concept of remanufacturing and waste-free process. Remanufacturing refers to equipment the whole life cycle theory as the instruction, in order to realize the waste equipment performance improvement as the goal, to high quality, high efficiency, energy saving, material saving, environmental protection for the guidelines, by means of advanced technology and industrialization production, repair, reconstruction of waste equipment, a series of technical measures or the floorboard of the engineering activities [3-4]. Remanufacturing process refers to all kinds of remanufacturing technology is used to repair and remanufacturing product processing, and remanufacturing product meets the performance after the process. Due to the damage form of 
remanufacturing products, the production organization form is different, so the specific production process will have differentiation. Usually, the remanufacturing process is shown in figure 1.

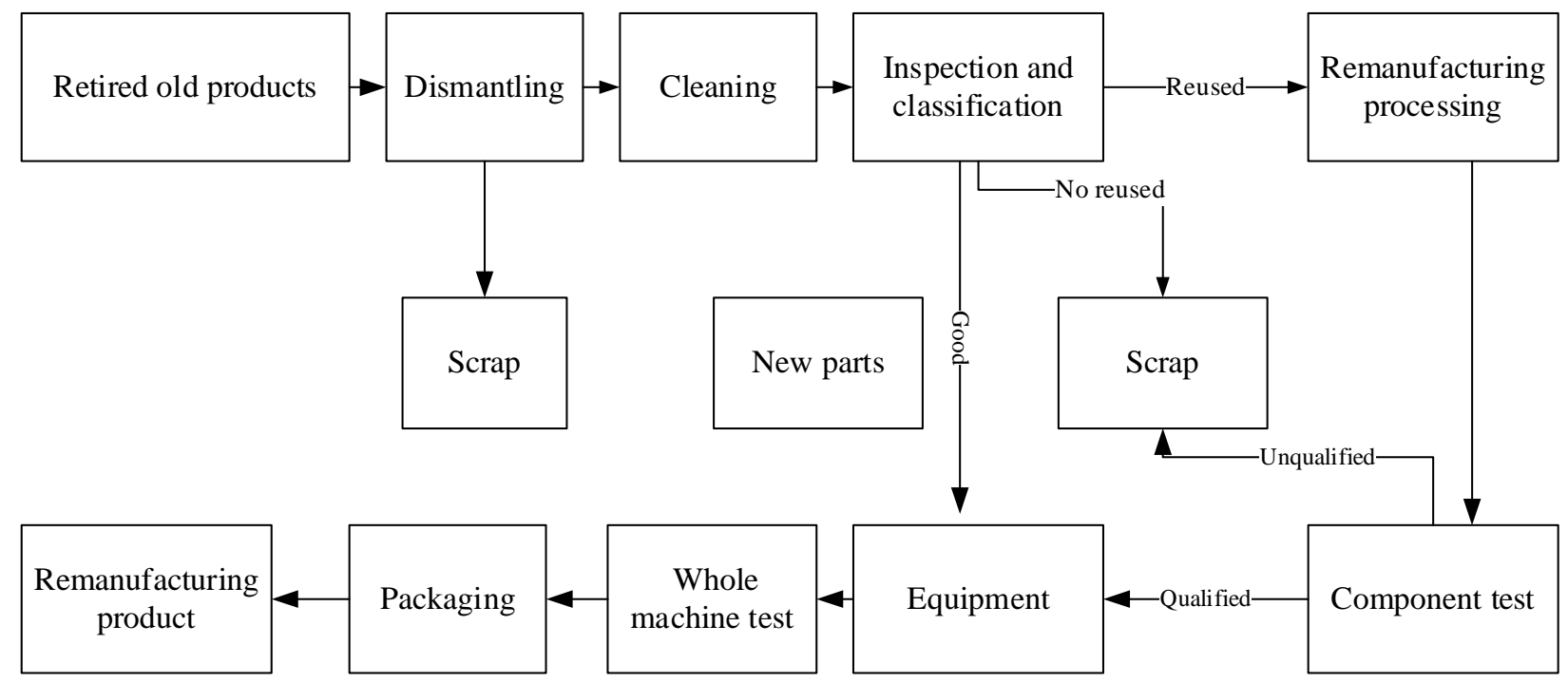

Figure 1.Remanufacturing process flow chart

\section{The remanufacturing process of engineering machinery key parts}

For remanufacturing companies are concerned about the remanufacturing, especially use of remanufacturing. In engineering machinery, most of the key parts are the core components, has given the larger inherent in the design of remanufacturing, so just consider its use of remanufacturing, but not all key parts fit or need to be made [5]. Although there are some key parts in performance has the key features and important characteristic, but its value is not necessarily high, sometimes belong to low quick-wear part, it's not worth for remanufacturing; And some of the parts under the condition of current technology and the remanufacturing cost is too high, probably more than the value of the new product, so it is not worth for remanufacturing. So only a certain range of key parts worth making. Value the failure or damage to the higher parts, mainly surface damage, and the internal key material usually have not damage, and is expected to pass remanufacturing technology to repair, restore its surface features, making them back into use. For parts, components shall be suitable for remanufacturing is value is higher, the function of its components may be failure or damage, but most of component parts (especially the main parts) has not yet been failure or through certain remanufacturing process can restore its performance, so as to restore parts of performance requirements. For recycling waste parts to the factory again, the remanufacturing process is shown in figure 2.

According to the analysis of the waste product remanufacturing process and manufacturing practice again, according to the production process, remanufacturing technology in general can be divided into: cleaning technology, dismantling technology and informatization of remanufacturing technology, painting and packaging technology, the running-in and experimental technology, parts processing technology, assembly technology, testing technology of the parts. 


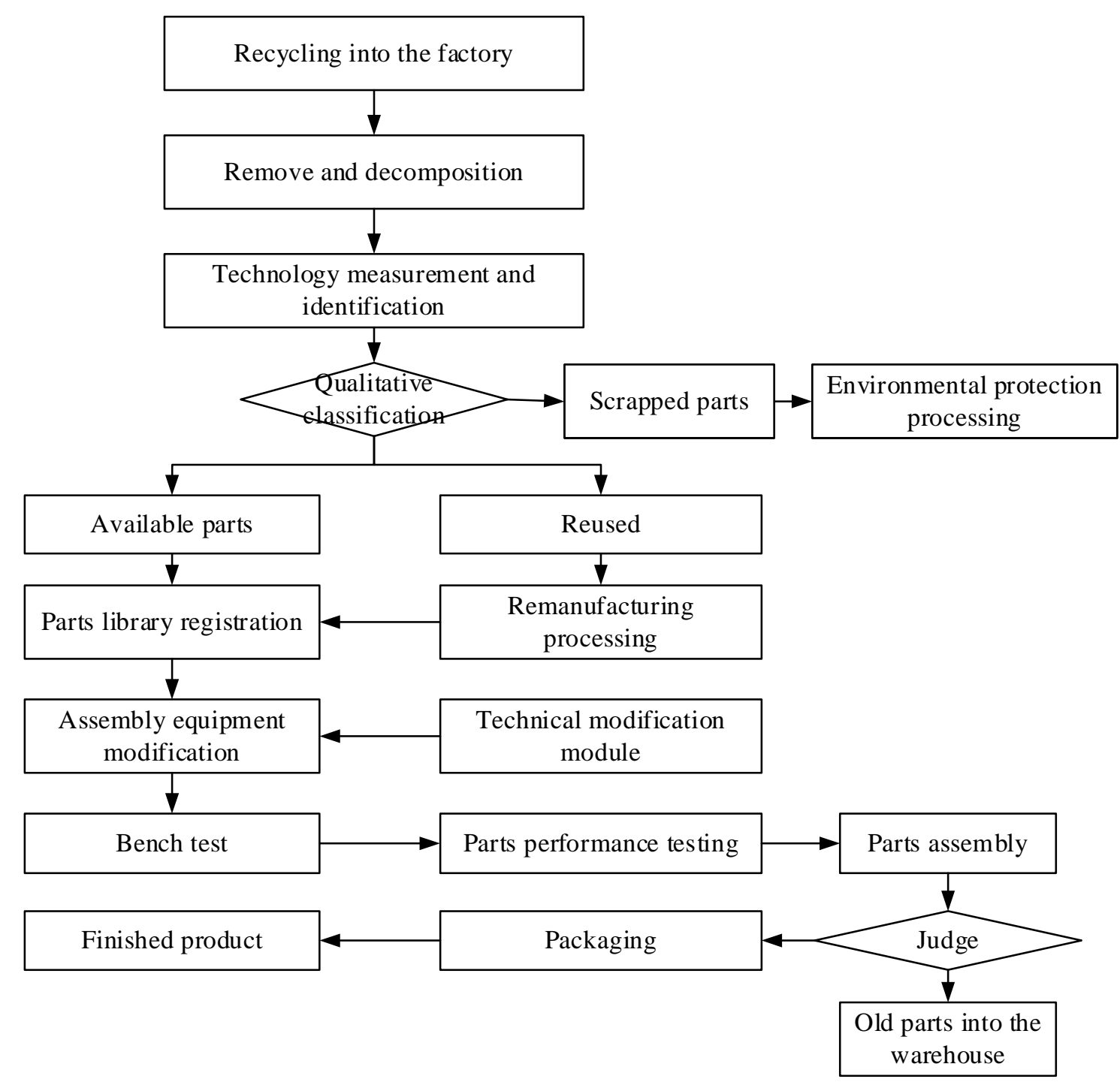

Figure 2. Parts or group remanufacturing process for engineering machinery

\section{The remanufacturing evaluation indicator system for Key parts of engineering machinery}

Engineering machinery remanufacturing comprehensive evaluation for the purpose of key parts is qualitative and quantitative evaluation of waste components for remanufacturing, due to the factors to consider more, thus formed an index system. According to the above principles, set up evaluation index system, evaluation of building engineering mechanical key parts system hierarchy, as shown in figure 3. Engineering machinery and key components in the abandoned and failure, whether remanufacturing and whether it worthy of remanufacturing, is to carry out the remanufacturing, before the problem before to manufacturers, whether it is worth for remanufacturing involves many factors, from the perspective of manufacturer again, mainly due to technical, economy and environment of several major aspects, in order to better evaluate, on several aspects of the corresponding index system is established.

Analytic hierarchy process (AHP) are often used to target and rule, multi-level, multi-factor complex decision-making problems. Engineering machinery remanufacturing characteristic key parts and the weight of index evaluation system need to consider many factors, and the correlation between indicators. Using the AHP method to determine the index weight, on the one hand, reduce the artificial factors on the index weight of external influence, on the other hand to establish the connection between the fuzzy evaluation of qualitative and quantitative accurate assessment, makes the evaluation model of feasible degree greatly increases the force. 


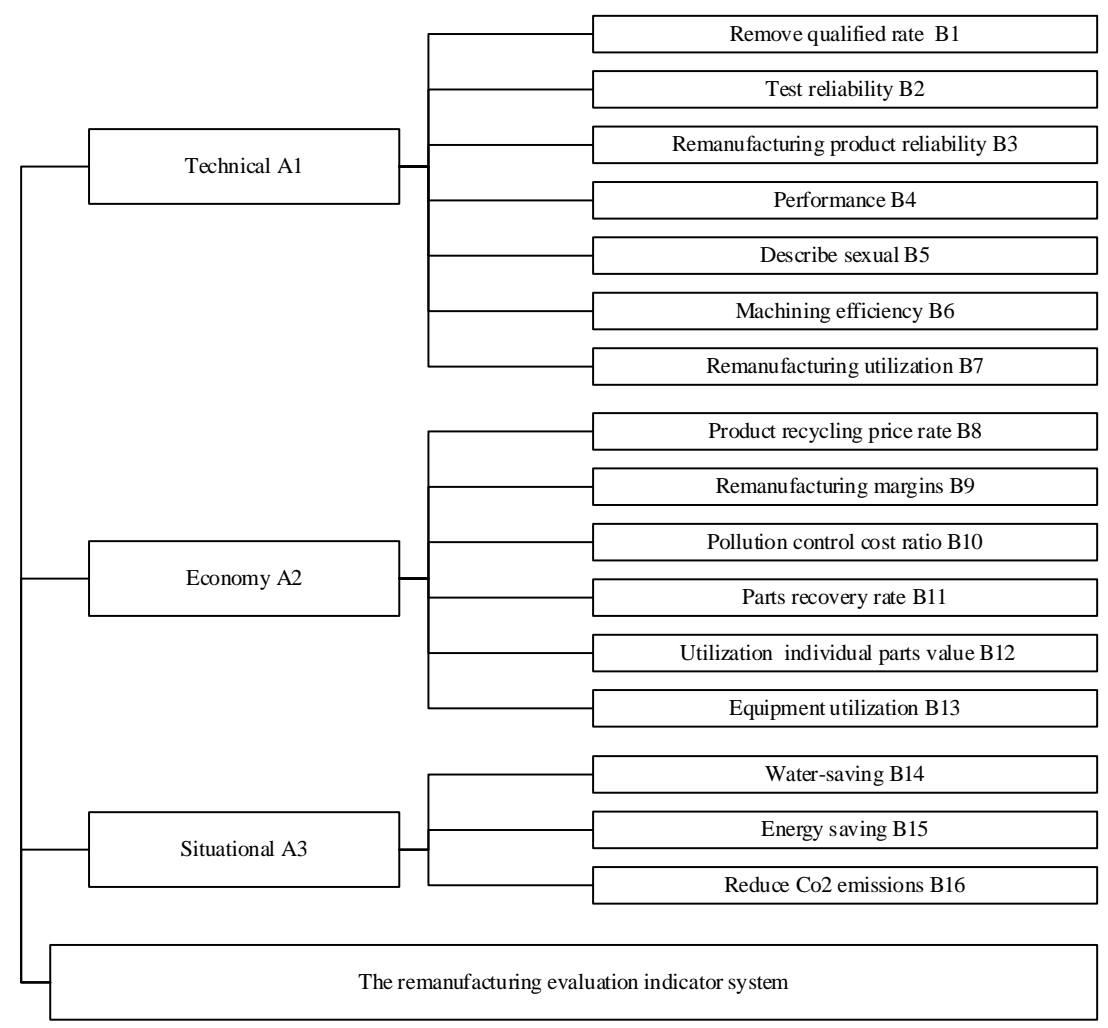

Figure 3. The remanufacturing evaluation indicator system for Key parts of engineering machinery

\section{Conclusion}

Remanufacturing as green manufacturing for the sustainable development of circular economy mode, the resource conservation and environmental protection play an important positive role, is more and more people's attention. This paper around the key construction machinery spare parts remanufacturing characteristic and evaluation, this paper analyzes and discusses first introduced the domestic and foreign research and development situation of remanufacturing has been clear about the construction machinery products and parts for remanufacturing has the positive significance and good prospect, this paper expounds the characteristics and classification of engineering machinery products, from engineering machinery operation features and performance requirements, manufacturing and sales of construction machinery is analyzed and discussed, the characteristics of hope by key parts of the engineering machinery products remanufacturing characteristic evaluation process and information analysis, build the evaluation system.

\section{Reference}

[1] H. Lin, G. Bo, and L. Haichun: Journal of Agricultural Mechanization Research, Vol.7 (2012), p. 8.

[2] Z. Shan, S. Qin, and Q. Liu: International Journal of Precision Engineering and Manufacturing, Vol.13 (2012) No.7, p. 1095.

[3] G.D. Hatcher, W.L. Ijomah, and J.F.C. Windmill: Journal of Cleaner Production, Vol.19 (2011) No.17, p. 2004.

[4] D. Zhang, D. Hu, and Y. Xu: Computers in industry, Vol.63 (2012) No.4, p. 328.

[5] E. Sundin, M. Lindahl, and W. Ijomah: Journal of Manufacturing Technology Management, Vol.20 (2009) No.5, p. 723. 